\title{
Del registro al archivo: el devenir de la imagen etnográfica en el Instituto Nacional Indigenista
}

\section{From Record to an Archive: The Becoming of Ethnographic Images within National Indigenist Institute}

\author{
Julieta I. Martínez López \\ Investigadora independiente, Ciudad de México \\ https://orcid.org/oooo-ooor-8784-9952 \\ julietmartinez@gmail.com \\ Tzutzumatzin Soto Cortés \\ Investigadora independiente, Ciudad de México \\ https://orcid.org/oooo-0003-4749-4530 \\ tzutzu56@gmail.com \\ ISSN-0185-4259; E- ISSN: 2007-9176 \\ DoI: http://dx.doi.org/10.28928/ri/912021/atc1/martinezlopezj/sotocortest
}

\section{Resumen}

El presente texto expone el contexto y las condiciones que dieron origen a la creación del Archivo Etnográfico Audiovisual (AEA) en el Instituto Nacional Indigenista (INI), hoy Instituto Nacional de los Pueblos Indígenas (INPI), con el objetivo de reconocer los discursos que configuran el impulso de generar y coleccionar imágenes etnográficas. El análisis indaga sobre qué le da la característica de archivo al AEA y cuáles son los discursos que al plantear el rescate de culturas proponen la preservación de imágenes reunidas en archivos.

Palabras clave: archivo, discurso, etnografía, cine indigenista, colecciones audiovisuales.

\footnotetext{
Abstract

This text exposes the conditions of creation of the Ethnographic Audiovisual Archive (AEA) in the National Indigenist Institute (INI), today the National Institute of Indigenous Peoples (INPI), with the aim of recognizing the discourses that shape the ethnographic archived image, in connection with urge to collect moving images. The analysis investigates what gives the AEA its archival characteristics and what are the discourses that, when proposing the rescue of cultures, propose the preservation of images gathered in archives.

Keywords: archive, discourse, ethnography, indigenous film, audiovisual collections.
}

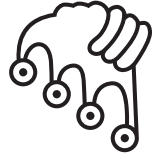

IZTAPALAPA

Agua sobre lajas 


\section{Introducción}

linterés por crear registros audiovisuales de los pueblos indígenas en con-
textos institucionales se desarrolló en México desde la década de i920. La
programación de actividades de generación y preservación de información etnográfica en el ámbito audiovisual fue errática en distintas entidades gubernamentales, hasta que en la década de los setenta se impulsó la creación del Archivo Etnográfico Audiovisual (AEA) dentro del Instituto Nacional Indigenista, un proyecto que surge en un momento en que la oposición a las políticas paternalistas e integracionistas que había instaurado el INI se nutren de la transformación en la práctica de las disciplinas antropológicas, como lo deja ver la publicación del título De eso que llaman antropología (1970), con aportaciones críticas de Arturo Warman, Guillermo Bonfil, Margarita Nolasco, Mercedes Olivera y Enrique Valencia a la política indigenista gubernamental. Ese texto se ha considerado por la historiografía sobre la institución como un parteaguas en la antropología mexicana que impactó en las acciones del INI, institución a la que en años posteriores se incorporaron algunos de sus autores (Lewis, 2018: 228-232) ${ }^{1}$

Los testimonios que dan razón de las motivaciones, elecciones y reflexiones de los realizadores que participaron en diferentes etapas del proyecto del AEA incluyen, en algunos casos, un análisis acerca de las particularidades de su forma de trabajo en relación con el cambio de ideología presente en el discurso del InI y que impactó en la creación de registros audiovisuales (Rovirosa, 1990; Novelo y Maldonado, 1997; Urrusti, 2010; Piñó Sandoval, 2013; Becerril, 2015). Estos recuentos se han centrado en reconocer los límites de la creación autoral, los procesos de investiga-

1 También habría que considerar las discusiones que en el ámbito internacional se daban en torno al indigenismo continental, como podemos observar en las sesiones de los Congresos Indigenistas Americanos, derivados del Instituto Indigenista Interamericano (con sede en la Ciudad de México), en las cuales el INI, y sus entonces críticos, participaron. 
ción etnográfica y la presupuesta censura institucional (Rovirosa, 1990), basados en la identificación de 37 documentales, aproximadamente 35000 fotografías, 300 horas de música grabada, siete libros de fotografía, cinco exposiciones y io discos de música, producidos desde la creación del AEA en 1977 hasta su transformación, que comienza en 1988 (Ahued, I988). ${ }^{2}$

Los discursos acerca de las motivaciones para producir un archivo son relevantes para analizar el caso del AEA; por ello, en las siguientes líneas proyectamos un recorrido que ubica su creación en el marco de una discusión sobre los archivos y las colecciones etnográficas en México, para sentar las bases de un enfoque pocas veces abordado: la manera en que se elaboran las imágenes etnográficas mediante la conformación y organización de archivos. Es decir, no solo de la creación de imágenes de pueblos indígenas, sino de la generación de repositorios de esas imágenes, lo cual supone una disposición sobre la forma en la que se crean, se seleccionan y descartan, se agrupan unas con otras, se narran a través de inventarios y catálogos y se discuten.

Hay discrepancias con respecto al número de películas realizadas por el AEA entre 1977 y 1988, principalmente porque se enuncian a partir de variables como el soporte (fílmico, en su mayoría en $16 \mathrm{~mm}$ ), el género fílmico (en su mayoría documentales que no daban paso a la ficción) y el tipo de proyecto en el que se inscriben (se consideran únicamente aquellas anteriores al Programa de Transferencia de Medios). Por ejemplo, Ahued menciona 37 películas (1988: 549) que incluyen la experiencia de Elvira Palafox, generadas como parte de un ejercicio previo al proyecto de Transferencia de Medios, y no contempla Encuentros de medicina maya (Urrusti, 1987). Por su parte, Becerril (2015:31) señala que fueron 38 los documentales del AEA en $16 \mathrm{~mm}$ y uno en $8 \mathrm{~mm}$, sin mencionar cuáles. Por otro lado, consideramos 1988 como el comienzo de la transformación en la forma de producción, pues aunque continuó como centro de producción hasta 1992, desde 1988 encontramos una discusión, motivada en parte por el aniversario cuarenta de la institución, en torno a la forma de producción y difusión de los materiales realizados en el AEA. Fue en 1989 cuando el AEA comenzó a realizar sus documentales en video (Baltazar, 2010: 17). No obstante, en 1990 se produjo Animación de tres cuentos infantiles Purépechas (Dominique Jonard) en soporte fílmico y en 1995 vio la luz El pueblo mexicano que camina (Juan Francisco Urrusti), también en soporte fílmico y con créditos del AEA. La organización actual de los fondos del Acervo de cine y video Alfonso Muñoz no permite hacer esta distinción por etapas, ya que tiene una lógica que desconoce estas diferencias (Ruiz y Vargas; 2003). Otro caso que ejemplifica esta complicación es Semana Santa entre los Mayos (Saúl Serrano, 1980), pues en la versión consultada no aparecen los créditos del AEA, ni de Fonapas pese al año de producción y a que algunas de las imágenes proceden de la primera etapa de registros del proyecto Ollin Yoliztli. En el siguiente vínculo se comparte un listado de la producción audiovisual del INI entre I95I y 1995: (http://archivomixtli.mx/php/documentos/ver_documento.php?idDocumento=19). 
En las siguientes líneas se expone una reflexión acerca de la creación de un archivo etnográfico, en primer lugar, por medio de una revisión historiográfica de la producción audiovisual que consideramos antecede a los registros y producciones del AEA, para entenderlos en el contexto de la generación de imágenes en torno a los pueblos indígenas de México en el ámbito institucional. En segundo lugar, nos centraremos en el análisis del funcionamiento del AEA y, por último, analizaremos desde una perspectiva archivística cuáles han sido los discursos que han hecho posible la organización de los materiales del AEA como un archivo, sus modificaciones y algunas ideas sobre las posibilidades que ofrece pensar el archivo como experiencia.

Han sido escasos los textos con perspectiva archivística respecto de la creación del AEA en su calidad de archivo, producto de una política de producción propia de registros y obras que se agrupan bajo ese nombre (Ruiz y Vargas, 2003; Baltazar, 2010). Partimos de la hipótesis de que la acumulación de imágenes en la lógica de coleccionar configura una relación con los sujetos que se registran, y ello entra en tensión con la forma en que se conocen esas imágenes dentro de una experiencia llamada archivo. Por ello, en este texto nos concentramos en la producción audiovisual del AEA para reconocer el impulso de preservar y la experiencia de hacerlo a partir de la creación de imágenes en movimiento como una experiencia de archivo (una, entre otras), producto cultural que se transforma.

La propuesta es reconocer qué tienen en común las iniciativas que, colocándose en el lugar de quien conoce y registra a los pueblos indígenas, buscaban también aprehenderlos como un conjunto de información. Este acto que definiremos como coleccionar se constituye por la relación entre quienes realizan los registros, los registros mismos y los seres humanos registrados en al menos cuatro momentos: en el planteamiento de las motivaciones para generar los registros audiovisuales, al hacer participar a los pueblos registrados en la realización, al editar las imágenes como una obra, y al coexistir obras y registros en el contexto de un archivo.

\section{La imagen institucionalizada}

La elaboración, recopilación y uso de documentos etnográficos deriva de las experiencias de conformación de acervos, resultado de la generación de registros y documentos a partir de las actividades propias de las instituciones y por la práctica coleccionista fundamentada en la idea del resguardo de materiales que den cuenta de las diferentes culturas que las producen. En este contexto, y en el del desarrollo de las disciplinas antropológicas, la adquisición y producción de material etnográfico 
de manera institucional, por medio de la creación de inventarios, responde, desde sus orígenes en el siglo XIX, a una intención de conocimiento de grupos humanos y su producción cultural, considerados en riesgo de pérdida ante la incidencia de los Estados nacionales en sus territorios.

Ante la elaboración de los primeros registros etnográficos filmados a finales del siglo $\mathrm{xIX}, \mathrm{y}$ principalmente en el $\mathrm{xx}$, fue necesario pensar en repositorios que hicieran posible su generación, colección, catalogación, estudio y preservación. La vía para la mayor difusión de los resultados de las investigaciones y el coleccionismo ha sido, en general, aunque no en forma exclusiva, la creación de los museos etnográficos; por ello resulta pertinente el papel que han tenido en la formación de colecciones audiovisuales. Podemos rastrear la importancia de captar imágenes en el estudio de pueblos indígenas y la tradición visual que se construyó a partir de ello, pues la observación era un punto esencial en la antropología desde el siglo xix (Massota, 2013:40). La fotografía tenía su lugar como herramienta en el quehacer científico del conocimiento de las culturas por su particularidad de registro testimonial, aunado a su supuesta neutralidad intrínseca (Naranjo, 2006: 18).

El Departamento de Asuntos Indígenas (DAI) se creó en 1936 para atender temas relacionados con las comunidades indígenas que anteriormente concernían al Departamento de Asuntos Agrarios. Ese mismo año se instituye el Departamento Autónomo de Prensa y Publicidad (DAPP), subordinado a la Secretaría de Gobernación, con el objetivo de apoyar la difusión de las tareas del gobierno de Lázaro Cárdenas con producciones audiovisuales y otros medios de comunicación (Vázquez Mantecón, 2012). Por otro lado, también se llevaron a cabo las Brigadas Cinematográficas, dependientes de la Secretaría de Educación Pública, que tenían como objetivo "imprimir películas con todo lo interesante que hay en cada una de las entidades federativas, tanto en el campo de las bellezas naturales como en las costumbres, industrias autóctonas y actividades regionales" (Torres San Martín, 2018: 169).

El DAPP produjo el cortometraje titulado Información Gráfica No. 1 (Felipe Gregorio Castillo, 1937), que contiene imágenes de la gira gubernamental de Lázaro Cárdenas por "las zonas más remotas del país", según el relato del narrador, que en voice over añade, con "plena de confianza, la provincia acude en masa ante el jefe de la nación a exponerle sus problemas"; se incluyen visitas a escuelas rurales para dar paso a imágenes de su estancia entre la "tribu" kikapú, donde el presidente escucha sus demandas, les entrega títulos de posesión ejidal de la tierra en que viven y recorre las inmediaciones donde van a emprenderse obras de irrigación. 
Dos años después, el DAPp produjo Centro de Educación Indígena Kherendi Tzitzica. Flor de las peñas (Felipe Gregorio Castillo, 1938). La película muestra un día en el internado indígena en Paracho, Michoacán, donde a un grupo de personas a quienes la voz del narrador identifica como indígenas participan de un programa educativo que pone particular atención en la higiene personal, la educación técnica y la enseñanza del castellano.

No obstante, el proyecto del DAPP no prosperó, pero por su parte el DAI se consolidaría en 1948 como órgano desconcentrado federal con la creación del Instituto Nacional Indigenista. Tres años más tarde, en 1951, se realizaron registros audiovisuales sobre el trabajo del Centro Coordinador Indígena (CCI) de San Cristóbal de Las Casas, Chiapas; en 1952 se crearon las ayudas audiovisuales, cuya función era contribuir a la divulgación, difusión y promoción de la labor de los CCI, los cuales formaron parte del modelo de acción regional. Para julio de 1954, la revista Acción Indigenista describía de la siguiente manera los materiales audiovisuales producidos por dicha sección: "Teniendo en cuenta que para los indígenas de Chiapas es necesario verse reflejados ellos mismos como sujetos a quienes van dirigidos los conocimientos, en una forma que permita observar los detalles propios de sus características culturales ha venido desechando la idea de producir transparencias aplicables a todos los medios indígenas" (Los materiales audiovisuales, 1954).

Así, la producción audiovisual del INI entre I95I y 1958 se concentró en el registro de las actividades del propio instituto, primero con el trabajo en los CCr y después con la demostración del impacto que sufrían las comunidades indígenas por las obras de infraestructura que se realizaban en sus territorios. De este periodo se encuentran en la sección de Cine y Video del acervo del actual Instituto Nacional de los Pueblos Indígenas (INPI), siete rollos fílmicos de $16 \mathrm{~mm}$ de registros sin editar, sin sonido y en blanco y negro, correspondientes al Centro Coordinador Tzeltal-Tzotzil en San Cristóbal de Las Casas ${ }^{3}$ y tres rollos fílmicos del registro de reacomodo de las poblaciones mazatecas y chinantecas por la construcción de la presa Miguel Alemán.

Estos materiales se utilizarían posteriormente en la primera producción editada por el entonces ini, Nuevos Horizontes (1956), con una duración de 40 minutos, a la que siguió Todos somos mexicanos (1958), de I2 minutos, realizadas por José Arenas con fotografía de Nacho López, y con la participación de Gastón García Cantú, Rosario Castellanos y Fernando Espejo como guionistas. Ambos materiales abordan la experiencia de los primeros trabajadores indigenistas: médicos, técnicos, ingenie-

3 Esto rollos se utilizaron en 2009 para la edición de Primeras acciones del INI, video en que se muestra la contrucción de escuelas y centros de salud. 
ros y promotores en el cci de San Cristóbal y, por otra parte, las afectaciones para la población mazateca a consecuencia de la presa Miguel Alemán en Oaxaca. Las imágenes de ambas producciones son las mismas; sin embargo, el tono del discurso cambia. Mientras que en Nuevos Horizontes la voz de Sonia Montero describe la situación de los indígenas retratados, y en ocasiones habla en primera persona, como si hablaran ellos mismos, en Todos somos mexicanos, la voz del locutor Fernando Marcos nos remite a la estructura de los noticiarios cinematográficos oficiales.

El interés por realizar Nuevos Horizontes se consigna en el número 34 de Acción Indigenista con un texto titulado "Película del INI", en el que se describe la necesidad de dar a conocer parte del trabajo que el Instituto había realizado con comunidades indígenas, quienes por diferentes razones no tenían acceso a libros, folletos, periódicos y memorias. Es así que: "una sencilla cámara portátil de $35 \mathrm{~mm}$, en las manos de Nacho López y bajo la dirección de José Arenas, ha sido suficiente para tener la primera parte de una película que abarcará, en veinticinco minutos de exhibición, partes de las regiones de Chiapas y Papaloapan" (Película del INI, 1956). El texto concluye apelando a la "ignorancia de la población mexicana respecto a la situación de los indígenas", y de ese modo se configura no solo un segundo objetivo para el uso del cine, sino una diferencia entre los habitantes del territorio mexicano: la población mexicana y los indígenas.

Mientras tanto, en el contexto internacional se consolidaron los primeros museos en albergar la producción fílmica antropológica. Casos como el del entonces Museo del Hombre en Francia, el Museo del Hombre/Museo de Historia Natural del Smithsonian Institution y el Museo Peabody de Arqueología y Etnología de Harvard, son algunos ejemplos de esta tendencia y resultan paradigmáticos para entender cuáles han sido las lógicas de la creación de este tipo de archivos.

En 1952 se creó en Francia el Comité du Film Ethnographique, fundado por Jean Rouch, el cual forma parte del Comité Internacional del Film etnográfico y sociológico instituido en 1952 a iniciativa de la Organización de las Naciones Unidas para la Educación, la Ciencia y la Cultura (UNESCO) y su misión era coleccionar, conservar y difundir los filmes de interés que existían, así como producir filmes etnográficos en el marco de las actividades del Museo del Hombre. Por otro lado, está The Film Study Center, del Peabody Museum, fundado en 1957 como un centro de registro y producción audiovisual, de acuerdo con los estudios etnográficos y arqueológicos que se llevaban a cabo en ese recinto (About the Film Study Center, s/f). Por su parte, el National Anthropological Film Center, (NAFC), hoy Human Studies Film Archives, se creó como resultado de una serie de decisiones institucionales por parte del Instituto Smithsoniano, entre 1960 y 1980, en torno a la necesidad de generar 
documentos no solo para la posteridad, sino para el estudio presente de las culturas en vías de extinción y de las problemáticas de la humanidad (Link, 20I6: I47). ${ }^{4}$

En México, los antropólogos y cineastas relacionados con la práctica etnográfica no fueron ajenos a estas discusiones. Garza Marcué y Mariño (2017: IIO-III) destacan la influencia que la experiencia francesa pudo tener en los jóvenes antropólogos y etnógrafos mexicanos que buscaban medios para compartir sus investigaciones, lo cual tendría un impacto en los centros de producción derivados de la labor museística, como fue el caso de Guillermo Bonfil, Arturo Warman y Alfonso Muñoz en el Museo Nacional de Antropología de México con su película Él es Dios en 1965. Por otro lado, una referencia continental respecto a la necesidad de hacer archivos etnográficos audiovisuales la encontramos en el vir Congreso Indigenista Interamericano realizado en Brasil, donde una de las recomendaciones fue la creación de museos etnográficos dotados, entre otras cosas, de cinematecas, así como la realización de películas educativas (Costa Cavalcanti, 1972).

A principios de la década de 1960, el Instituto Nacional de Antropología e Historia (INAH) produjo, a través de su Departamento de Cine, fundado en I960 por Alfonso Muñoz, ${ }^{5}$ y de la Sección de Etnografía del Museo Nacional de Antropología (MNA), creado en 1964, un conjunto de documentales que abordan la realización de festividades en comunidades de Oaxaca, Morelos, Querétaro, Puebla, Nayarit y Sonora. ${ }^{6}$ En esta experiencia colaboraron antropólogos y etnógrafos como Gastón

4 Cabe señalar que este centro no solo fue productor y recolector de imágenes propias, sino que se planteó como un repositorio para la preservación tanto de producciones externas que de manera contemporánea se generaron, como para los primeros registros fílmicos etnográficos (History of the Human Studies Film Archives, s/f).

5 Alfonso Muñoz se formó con José D. Kimball en el Instituto Latinoamericano de la Cinematografía establecido el 30 de mayo de 1950 por acuerdo entre el Gobierno de México y la unesco. A partir de 1977 colaboró en el AEA.

6 Esta, sin embargo, no fue la primera experiencia de este tipo dentro del museo. En 1922, siendo el Museo Nacional de Arqueología, Historia y Etnografía con apoyo del Departamento de Bellas Artes de la Secretaría de Educación Pública, presentó "una película cinematográfica de vulgarización científica”, según se lee en el primer intertítulo de Peregrinación a Chalma, resguardada en el acervo de la Filmoteca de la UnAm. Un intertítulo posterior señala que se trata de una película cinematográfica complementaria del estudio etnográfico del Santuario de Chalma realizado por el Departamento de Etnografía Aborigen. Se presentan ante la cámara Luis Castillo Ledón, director del Museo, Miguel O. de Mendizabal, jefe del Departamento de Etnografía Aborigen, Enrique Juan Palacios, arqueólogo e historiógrafo y el presbítero Canuto Flores, etnólogo, antes de comenzar la presentación de la fiesta que celebran los "aborígenes" en el primer 
García, Lina Odena Güemes, Barbro Dahlgren y Francois Lartigue junto a los realizadores Óscar Menéndez y Fernando Cámara. Asimismo, el INaH conformó su propia Cinemateca ${ }^{7}$ en 1967 con Galdino Gómez a la cabeza, quien, además de coordinar la exhibición de las películas producidas por la institución, gestiona la realización de ciclos de cine internacional y la adquisición de copias, tanto de materiales nacionales como extranjeros, emulando el espíritu de trabajo de la Cinemateca Francesa, para lo cual dedicaba realmente su trabajo en la Cinemateca. ${ }^{8}$

La expectativa acerca de las posibilidad del registro fotográfico se puede ver, por ejemplo, en la construcción de las salas de etnografía del Museo de Antropología de México. A partir de I96i se planteó realizar 70 "expediciones etnográficas", que tenían como prioridad ir a las zonas de grupos que no se hallaran suficientemente representados en el acervo del museo, o bien que estuvieran en "vías de transformación” (Sierra, 1994: 89). Este proyecto estaba organizado para que se recopilaran diferentes materiales en un solo viaje: registros lingüísticos, fotográficos, sonoros, dibujos, objetos, notas de trabajo de campo y filmaciones (Sierra, 1994: 83)

Los materiales recopilados permitieron incrementar los acervos del museo, actualizarlos, conformar una nueva clasificación de objetos y repensar la manera de construir las salas etnográficas, pues más allá de tener elementos para su exposición, contaban con materia prima para la investigación y la configuración de los pueblos representados. Estas prácticas estaban inmersas en el interés por la generación de acervos especializados que heredarían una tradición archivística en su concepción, tal como el Instituto Nacional Indigenista en la conformación del AEA, que se inscribe en una línea institucional de elaboración de materiales audiovisuales referentes a las comunidades indígenas, como parte de la producción fílmica de la actividad gubernamental que se puede rastrear desde el periodo cardenista (I934-I940).

viernes de cuaresma.

7 La Cinemateca Mexicana del INAH fue la primera institución mexicana en formar parte de la Federación Internacional de Archivos Fílmicos (FIAF) como miembro asociado, en el periodo de 1970-1974, y como observador de 1974-1978. La Filmoteca de la UnAM y la Cineteca Nacional se incorporan en 1975 (Historia de afiliación de la FIAF, s/f).

8 En 2013 la Cineteca Nacional realizó un proyecto de revisión, catalogación y digitalización de una selección de materiales de la custodia del INAH que se encuentran en sus bodegas desde el 20II, en colaboración con Apoyo al Desarrollo de Archivos y Bibliotecas en México A. C. (ADABI), según se consigna en el expediente de esta institución (Rescate de la Colección, 2013). Trece de estos materiales pueden consultarse a partir de 2020 en la lista de reproducción Miradas al acervo del canal de Youtube de la Cineteca Nacional. 
Mientras tanto, la Sep formuló Cine Difusión SEP para producir materiales en los que se informara del trabajo de la Secretaría de Educación Pública. Uno de ellos es Los triques de San Juan Copala (Héctor Ramírez, 1975), cortometraje sobre las metodologías que utilizan los investigadores del Instituto de Investigación e Integración Social del Estado de Oaxaca (IIISEO) para analizar, recopilar y estudiar el idioma triqui. ${ }^{9}$

En este contexto de producción cinematográfica instituciona ${ }^{10}$ en torno a las comunidades indígenas, y la consecuente acumulación de registros audiovisuales generados por su propia actividad, se inscriben las primeras incursiones en la producción audiovisual profesional del INI, a través de proyectos de índole documental. Romero Ugalde (1991* 33) informa de la realización cinematográfica indirecta por parte de este instituto con To find our life (Furst, 1969), producida por el Latin American Center de la University of California at Los Angeles (UCLA) con la cooperación y asistencia del Centro Coordinador cora-huichol, cuyo director en ese momento era Salomón Nahmad, quien posteriormente sería director del INI.

Misión de Chichimecas (Nacho López, 1970), cortometraje que pretendía dar constancia de las acciones gubernamentales, contó con la colaboración y participación del Gobierno de Guanajuato y de la Secretaría de Salubridad. Otras dependencias, como la Secretaría de Agricultura y Recursos Hidráulicos (SARH) también coproducirían documentales con el INI. Por otra parte, con el grupo independiente Cine Labor, ${ }^{11}$ el INI realizó dos documentales antes de la instauración del AEA: Iñosavi (Tlaxiaco, tierra de nubes) de 1972 y Xantolo (Celebración del día de muertos)

9 Otro material que reconoce en sus créditos de producción al Instituto de Investigación e Integración Social del Estado de Oaxaca es Cine documentos IIISEo (2) Intercambio (1973), el cual se centra en la visita de cuatro niños provenientes de la República Popular de China que llegan a Oaxaca para estudiar español en el Instituto.

${ }^{10}$ En el ámbito de las experiencias cinematográficas independientes se encuentran aquellas personas que comenzaron a incluir en sus documentales a poblaciones marginadas. Un ejemplo es el Grupo Cine Testimonio, fundado en 1972 por Eduardo Maldonado, Francisco Bojórquez, Ramón Aupart, Renato Rabelo y Raúl Zaragoza, realizadores de varios documentales centrados en las problemáticas de los campesinos. Maldonado, quien más tarde filmaría un par de películas en el AEA, hizo Testimonio de un grupo (197I) junto a Jaime Humberto Hermosillo y Francisco Bojórquez, documental que muestra a una agrupación de campesinos del Estado de México enfrentándose a la corrupción estatal, y que aborda un punto que será retomado más tarde por Maldonado en sus colaboraciones con el INI: el del registro de las comunidades mestizas, según las clasificaciones étnicas del propio INI.

${ }^{11}$ Conformado por Olivia Carrión, Epigmenio Ibarra, Gonzalo Infante y Scott S. Robinson. 
de 1973. A partir de estas experiencias el instituto consideró dedicar recursos en su propia área de producción audiovisual a través del presupuesto proveniente del Fondo Nacional Para Actividades Sociales (Fonapas) en $1977^{12}$

\section{Registro y obrał la creación del AEA}

El AEA se derivó del área de patrimonio cultural del INI y sus actividades tenían objetivos de "rescate, conservación y defensa del patrimonio cultural indígena", según el documento que recupera Romero Ugalde (I99I: 34), "Bases para la acción, I977I982"; el INI plantea como actividades prioritarias: "Promover la integración, sistematización y complementación de la información referente al patrimonio cultural de los diferentes grupos étnicos, a través del material gráfico, documental, publicaciones, grabaciones, filmaciones y fotografías de todo tipo de expresiones culturales" con la finalidad de darle difusión. Esto en el marco del convenio realizado con Fonapas, que a nivel nacional impulsó no solo el desarrollo social, sino cultural en diferentes ámbitos de las artes y en múltiples estados de la República mexicana.

Entre 1977 y 1982 se construyeron las bases materiales para la formalización del AEA con el financiamiento del Fonapas, mediante un convenio de colaboración con el InI que dio pie a la creación del Programa Ollin Yoliztli de Rescate Cultural de los Grupos Étnicos, "orientado a enriquecer el archivo etnográfico del propio instituto, por medio de registros fílmicos, sonoros y fotográficos de las características sociales y culturales de las comunidades indígenas del país" (Convenio, 198I), consecuentes con los objetivos del INI en ese periodo que eran "lograr el equilibrio entre el acceso a la modernidad económica, el respeto a la diversidad cultural y la participación y el fortalecimiento de la identidad nacional" (INI, 20I2: 15). Sus funciones oscilaban

${ }^{12}$ El fideicomiso Fonapas fue creado por decreto presidencial en enero de 1977, y tenía como finalidad allegarse los recursos necesarios para la realización de "actividades culturales y de bienestar social que desarrollan los organismos públicos" (DOF, 1977: 6). Por medio de este fideicomiso se crearon convenios estatales e institucionales que permitieron, entre otras cosas, la construcción de infraestructura cultural (como es el caso del Centro Cultural Tijuana o el Centro Cultural Ollin Yoliztli), apoyos y premios (Premio Fonapas-INBA, precursor del INBA-UAM de danza), publicaciones artísticas y culturales en coedición con varias instituciones (SEP, INI, INBA, gobiernos estatales), entre otras actividades. En el caso del INI, aparte de la publicación de libros de texto y fotográficos sobre comunidades indígenas, se apoyó la creación del AEA, bajo un convenio de colaboración denominado Programa Ollin Yoliztli. 
entre la investigación (necesaria para la elaboración de guiones o de estrategias de registro), el registro, la producción, la difusión y la recopilación de materiales sobre las comunidades indígenas que resultaban de interés para el instituto, sobre todo en el marco de operación del convenio Fonapas- Coplamar (Convenio, 198I). ${ }^{13}$

El informe de actividades del Programa Ollin Yoliztli correspondiente al periodo del I de octubre de 1977 al 30 de enero de 1978, que recupera Franco Rojas (2020), menciona I2 proyectos de registros realizados en el siguiente orden: Guerrero (I), Oaxaca (3), Baja California Norte (I), Sonora (2), Michoacán (I), Nayarit y Jalisco (I), solo Nayarit (I), Durango (I) y Chihuahua (I), de los cuales se obtuvieron aproximadamente 36 horas y media de imagen en movimiento, 6I horas de grabaciones de sonido y Io II 4 fotos fijas en blanco y negro y a color. Estos proyectos iniciales del AEA se modificarían geográficamente en 1979, cuando se dio prioridad al trabajo en la cuenca del Golfo de México por "el alto índice de población indígena con manifestaciones culturales plenamente diferenciadas y el acelerado proceso de transformación en que se encuentran debido al desarrollo de la industria petrolera en dicha zona" (Ruiz y Vargas, 2003: 10).

A pesar de que para 1982 el dinero destinado al AEA incluía la edición de discos y libros, así como la de material recabado y posproducción de películas (Convenio, 198I), al menos en los primeros cuatro años los informes del AEA expresan que la intención principal fue la generación de materiales (imágenes, sonido, documentos) para, entre los objetivos mencionados, apoyar la investigación antropológica (Ruiz y Vargas, 2003: 33), ya que, como menciona Ahued (1988:54I),"el objetivo inmediato era la constitución del acervo". Al respecto, el cineasta Óscar Menéndez caracteriza estos primeros años como aquellos en los que la recopilación para la generación de un archivo con imágenes de expresiones indígenas era motivo de un debate interno

${ }^{13}$ En 1977, como parte de las políticas de atención social del gobierno de José López Portillo, se creó la Coordinación General del Plan Nacional de Zonas Deprimidas y Grupos Marginados (Coplamar), del cual el INI, entre otros organismos de gobierno, se vio beneficiado con un presupuesto que buscaba incidir en los renglones de salud, educación, alimentación y vivienda de grupos marginados pertenecientes en un alto porcentaje a alguna comunidad indígena. En este sentido, la Coplamar, en coordinación con otras instituciones, recopilaría información, "realizaría estudios de la situación vigente y las demandas principales de los grupos marginados en el país y, a su vez, buscaría que distintas instituciones resolvieran estas necesidades en regiones específicas" (40 años de estrategias, 20r8: 47). Esta situación influyó en la manera en que se desarrollaron los proyectos del INI (que, a su vez, era la institución coordinadora de la Coplamar), incluyendo, inevitablemente, los que se produjeron en el marco del AEA. 
sobre el uso de las imágenes producidas. En una entrevista realizada por José Rovirosa en abril de 1986, describe la discusión de la siguiente manera:

el proyecto era verdaderamente de un conductismo feroz; se forma con la idea de recoger las expresiones indígenas para clasificarlas y guardarlas para los investigadores. Ese es el proyecto del archivo etnográfico, yo desde el primer momento me opongo rotundamente a ese tipo de trabajo, pero sin ninguna fuerza de carácter operativo. Entonces, hago una trampa de cineasta; ya que se había recogido bastante material a través del compañero Gonzalo Martínez, que fue el primer jefe junto con un equipo de carácter priista que quería aprovecharse políticamente del archivo. Recogían imágenes de fiestas, de cosechas, de modos de vida, sin ningún orden, simplemente para acumular el material (...) “vamos a ver realmente qué sucede; a ver si podemos impulsar este proyecto a través de un material cinematográfico” (...) Se aprobó ese plan de recoger la información a través del cine, esa era la primera parte de la trampa. La segunda fue la realización de este material y, la tercera, a pesar de la oposición del mismo instituto, montar la película para mostrarla organizadamente, no como una especie de registro nada más, sin pies ni cabeza. Armar una película en su primera versión, en doble banda, nada más para que los funcionarios pudieran tener una correcta idea de lo que pasaba en la sierra. Obviamente, era tan impactante el mensaje ya organizado como película, y no solamente por las tomas fraccionadas, que de repente, sin proponérselo, estaba la primera película del instituto. Como estaba ese proyecto terminado, los dirigentes del instituto, más arriba de Salomón Nahmad, se dieron cuenta de la vena que tenía esto para promoverse ellos como funcionarios: "miren, también hacemos películas". A través de una trampa se logra en esa etapa del archivo hacer películas en el instituto, porque no había proyecto de hacer películas. Esa es la historia de La música y los mixes, que es una trampa (Rovirosa, 1990: 72).

Aunque posteriormente el INI por medio de sus publicaciones (Ruiz Mondragón y Vargas, 2003:33) recupera la idea de Menéndez, al mencionar que las primeras filmaciones tuvieron la intención de generar un banco de registros (imágenes fijas, en movimiento y sonoros), su testimonio apunta también a definir el registro como una producción objetiva incompleta que solo alcanza su verdadero valor al ser interpretada por la creatividad del cineasta, por ejemplo, en la realización de documentales considerados como obras. ${ }^{14}$ Esta visión, quizá, ha generado la idea

${ }^{14}$ Realizadores independientes y jóvenes egresados de las escuelas de cine encontraron 
de que el AEA era solo un centro de producción circunscrito a la creación de más de 30 películas, sin considerar que también se trataba, a su vez, de un repositorio de documentos en soportes múltiples que en su devenir conformaría un acervo en torno a las comunidades indígenas y la labor del Instituto en ellas.

Alrededor de 1980 se consideró la elaboración de un catálogo con criterios específicos de clasificación y acceso de los materiales basado en la "Guía para la clasificación de materiales culturales" de Murdock, ${ }^{15}$ utilizado en el campo de la antropología, lo que habla de un interés por el ordenamiento según los parámetros que en ese momento se tenían con respecto a la clasificación de las prácticas culturales en el plano etnográfico, con base principalmente en tablas de materias, aunque en los Lineamientos del AEA también se consideraron otros campos como grupos étnicos y soportes (Lineamientos, 1980)

Y aunque esta propuesta de ordenamiento y catalogación de los materiales del AEA no se llevó a cabo como estaba previsto, es importante considerar que cuando se elaboraron los primeros trabajos de catalogación, en la década de 1990, ya existía un antecedente de su resguardo.

Los materiales creados por el AEA se localizan actualmente en el INPI, como parte de su Centro de Investigación, Información y Documentación de los Pueblos Indígenas de México (сігр⿱亠䒑)), conformado el 4 de diciembre de i998. Fue en 2002, después de un proceso de reorganización con perspectiva archivística, que los fondos documentales procedentes de los departamentos que operaban en el AEA se reagruparon para encontrar lugar en una nueva estructura administrativa. A partir de ese año se nombran de manera independiente como: Acervo de Cine y Video Alfonso Muñoz, Fonoteca Henrietta Yurchenco y Fototeca Nacho López. ${ }^{16}$

en los espacios de creación audiovisual institucional como el AEA, Cine Difusión SEP, el Centro de Producción de Cortometrajes (CPC) o en las universidades una puerta para entrar en el mundo cinematográfico, el cual para finales de la década de 1970 todavía estaba regido por la voluntad de los sindicatos, que restringían la entrada a nuevos creadores.

15 Elaborada por George Peter Murdock alrededor de 1937 y que fue actualizada en varias ocasiones, así como traducida al español (Guía, 1989).

${ }^{16}$ En la página oficial del InPI se describe que el cirdpim se compone de: Acervo de Arte Indígena, con más de 23000 piezas originales del siglo xvir a la fecha. Acervo de Cine y Video Alfonso Muñoz, con casi 3000 cintas cinematográficas y 13000 videos documentales. Biblioteca Juan Rulfo, que incluye los fondos: bibliográfico con 45000 títulos, hemerográfico con 8 000, documental histórico con I4 000 y cartográfico con I3 000. Fonoteca Henrietta Yurchenco, con más de II ooo registros sonoros que incluyen mú- 
Esta reorganización, basada en un criterio que privilegia la división por soporte (audiovisual, audio e imagen fotográfica), responde no solo a una política de preservación sino a una necesidad de aglutinar los diferentes fondos que se generaron desde que inició la operación del InI y no únicamente los creados por el AEA.

En 2002 se conceptualizó el Acervo de Cine y Video y se bautizó con el nombre de Alfonso Muñoz, ${ }^{17}$ quien había contribuido a la creación del AEA y en algún momento criticó el predominio del interés cinematográfico sobre el antropológico (Rovirosa; 1990). Esta situación parecía común en el marco de instituciones con vocación antropológica, como ocurrió en proyectos similares en Francia y Estados Unidos. ${ }^{18}$

El acervo Alfonso Muñoz se organiza en dos grupos según el soporte: cine y video. El primero se subdivide en tres fondos: Producciones terminadas, Fondo de Producciones Inconclusas o Material de Stock y Fondo de Producciones Externas. El grupo de video, por su parte, se organiza en nueve fondos: Fondo de Producciones Terminadas INI-CDI, Fondo de Producciones Inconclusas o Material de Stock, Fondo de Diplomados y Seminarios, Fondo de Videastas Indígenas, Fondo del Centro de Video Indígena de Michoacán, Fondo del Centro de Video Indígena del Noroeste, Fondo del Centro de Video Indígena de Oaxaca, Fondo del Centro de Video Indígena de Yucatán, Fondo de Producciones Externas y Fondo de Comunicadores Indígenas.

sica y narraciones orales del pasado y el presente. Fototeca Nacho López, con más de 350000 imágenes de 1890 a la fecha. Treinta Centros Regionales de Información y Documentación, ocho Archivos Históricos y 2I Fonotecas del Sistema de Radiodifusoras Culturales Indigenistas en los estados de la República. (https://www.gob.mx/inpi/ articulos/los-acervos-documentales-del-inpi-catalogo-en-linea).

${ }^{17}$ No debe confundirse con el Archivo Alfonso Muñoz, propiedad de la familia Muñoz Güemes. A raíz de la muerte de Muñoz en 200I, la doctora Lina O. Güemes Herrera se propone la organización y preservación de los documentos de la trayectoria del cineasta que son principalmente textos y fotografías. Véase Barrón Sanabria (20II).

${ }^{18}$ Jean Rouch, fundador del Comité du Film Ethnographique en Francia, dejaba de lado la tarea de hacer un cine enfocado en las tendencias de la etnografía francesa de esa época, a la par que se creaba una escuela cinematográfica particular que impactaría en la manera de filmar la otredad y de entender el papel del antropólogo en ello: el cinema verité. En medio de las discusiones sobre el papel del cine en la antropología, Rouch se inclinaba a apostar por el "cineasta etnógrafo sobre la dupla de investigador y cineasta", es por ello que a partir de 1956 se comenzaron a impartir cursos de iniciación cinematográfica para los científicos sociales (Gallois, 2009). 
Las motivaciones que impulsaron la reorganización de los materiales generados por la institución se expresaron en los siguientes términos: "conservar y difundir las manifestaciones sociales y culturales de los pueblos indígenas" (INI, 2012: 15) y, según su manual de organización, "fomentar el derecho de los grupos étnicos a preservar, transformar y desarrollar sus culturas, sin que esto constituyera un obstáculo para que hicieran valer sus reivindicaciones económicas y sociales" (Ruiz y Vargas, 2003:I0). Esta reorganización constituye el estado actual en el que se experimenta la relación entre quienes generaron registros, los editaron como obras, los administran como documentos de archivo y aquellos que fueron retratados.

En la expresión de estas motivaciones se pueden identificar conceptos sobre la noción de archivo con los que se define el impulso de coleccionar, desde la creación del AEA en 1977 hasta su integración al proyecto del CiIDPim en 1998. Encontramos que las motivaciones para la formación de colecciones etnográficas en los museos de las naciones colonizadoras a mediados del siglo xx y que hicieron de la práctica fílmica una herramienta para sus objetivos se pueden contrastar con los intereses que expresaron aquellos que dieron forma a la producción audiovisual dentro del INI, ya fuera por contradecirlos o por sus similitudes.

\section{Disputar la interpretación a través de discursos de preservación}

La generación de registros visuales de los pueblos indígenas en México, al igual que en otras latitudes, fue una política estatal, al igual que la formación de repositorios documentales para resguardar el presente para la posteridad, ante el temor (justificado) de la desaparición o por lo menos transformación (que traía consigo una sensación de pérdida) de los pueblos y sus culturas.

Esta respuesta tanto de la etnografía en particular como de la antropología en general intentaba prevenir la transformación y en algunos casos el exterminio de las culturas y sus manifestaciones que en un caso extremo ya no podrían formar parte del catálogo de culturas del mundo y que, por lo tanto, era necesario capturar, registrar, sujetar, ordenar y clasificar, para "constituir archivos etnológicos que puedan ser consultados por sus contemporáneos y conservados para el futuro” (Laferté, 2017).

Al observar el caso del AEA, habría que considerar que los registros audiovisuales, además de dar información acerca de las comunidades retratadas, permiten observar la manera en que se concibe el registro para aprehenderlas y conocer los criterios científicos, técnicos y narrativos que les dieron origen, así como la manera en que han sido resguardados, ordenados y categorizados como documentos. 
¿Cuáles son los desafíos en cuanto a la preservación de los registros de la diversidad humana? Por un tiempo fue el coleccionismo del gabinete de curiosidades, posteriormente los museos y después se dio paso a los archivos específicamente creados para ese propósito, generados de manera sistemática con una finalidad precisa de conservación, clasificación para el conocimiento y para sustentar la conformación de discursos sobre el tema, configurando como primer destinatario al investigador y no necesariamente a los miembros de las comunidades registradas.

Al observar los cambios que se han operado entre la creación del AEA y la incorporación de los materiales derivados de su actividad al Acervo de Cine y Video del INPI, divididos entre las producciones terminadas y los materiales sin editar $y$ organizados por la identificación de su producción y uso, presuponiendo su funcionalidad para la consulta actual, nos preguntamos si sería posible configurar otras narrativas de archivo desde la voz de quienes fueron filmados.

En el caso mexicano, la decisión de incluir temas etnográficos en los discursos fílmicos gubernamentales puede ser rastreada hasta los inicios del siglo $\mathrm{xx}$, teniendo particularidades formales y narrativas que los diferencian de otro tipo de producciones y que nos permiten reconstruir los discursos que dieron forma a los conceptos y categorías que impactaron en la generación de repositorios específicos, como fue el caso del Archivo Etnográfico Audiovisual.

A lo largo de estas líneas se expusieron las motivaciones para generar, coleccionar, preservar y difundir materiales audiovisuales en México como expresiones de una pulsión archivadora generada por la necesidad de orden, en este caso sobre los grupos humanos que se categorizan como indígenas. Las razones para acumular $y$ organizar su experiencia y memoria en forma de archivo han experimentado algunos cambios con respecto a la manera en la que se producen; sin embargo, durante el proceso de investigación de este texto no se encontraron debates relativos a su interpretación, disponibilidad y organización.

Si bien en la mayoría de los testimonios se recuperan las experiencias de exhibición de las obras editadas que significaron un estímulo anímico para la continuidad de la producción audiovisual, estas construyeron espacios intermitentes de debate al interior de la institución y con las comunidades. No obstante, aún queda pendiente el análisis de la recepción en esta modalidad de encuentro de los pueblos con las producciones realizadas.

Para abordar el caso del AEA como experiencia de archivo pusimos énfasis en cómo las pulsiones de coleccionar se ven exacerbadas en el caso de la imagen etnográfica, al estar relacionadas con la administración de la desaparición cultural; sin embargo las imágenes producidas y almacenadas en el contexto de este repositorio 
institucional requieren miradas diversas que interpelen la forma en la que se presentan y se nombran como ejemplares de archivo. ${ }^{19}$

Como se puede intuir, la riqueza del material generado en esta como en otras instancias no se reduce a lo que se asume como obras, sino que radica también en los llamados registros, los cuales, al ser resultado de un afán de preservación, deberían no solo estudiarse sino ponerse en un espacio de diálogo. Estos registros, inscritos en una tradición de la producción audiovisual como medio de difusión o de documentación, se generaron por el interés de contar con material que permitiera el análisis y estudio de las realidades indígenas, para la atención de problemas sociales mediante la aplicación de políticas públicas como el establecimiento de Centros Coordinadores, instalaciones de salud, educación, abasto, entre otras. No obstante, el estudio, acceso y reinterpretación contemporánea de esas imágenes y el acervo que las reune no está limitada a la función inmediata en el momento de su creación, sino que puede dar pie a múltiples caminos, casi siempre derivados de la manera en que tenemos acceso a ellas.

Los datos (imágenes y sonidos) no necesariamente fueron recolectados para convertirse en estadísticas o para ser exhibidos detrás de una vitrina o montados en una mampara, sino para tener herramientas para la intervención social. Por ello, no podemos reducir su intención a una mera idea de rescate de testimonios ante su inminente desaparición, sino también fueron realizados como una forma de intervención. Esto nos lleva a pensar que es necesario construir escenarios en los que quienes requieran encontrarse en las imágenes de aquellos que fueron retratados puedan hacerlo, conociendo el contexto de su creación con la posibilidad de hacer su propia interpretación, no necesariamente mediada por aquellas películas que se reconocen como obras, sino desentrañando la lógica archivística que las categoriza. Se suele desdeñar este tipo de registros por su carácter "propagandístico" de las políticas indigenistas estatales; sin embargo, no podemos reducir la complejidad de

19 Un ejemplo de autocrítica institucional es la del Peabody Museum of Archaeology and Ethnology at Harvard, cuyo catálogo virtual advierte: "Los registros de las colecciones pueden contener un lenguaje que refleja prácticas de recolección y métodos de análisis pertenecientes al pasado, que actualmente ya no resulta apropiado. El Museo Peabody está comprometido con la atención del problema del lenguaje ofensivo y discriminatorio presente en sus bases de datos. Nuestro equipo está constantemente actualizando estos registros, aumentando y mejorando su contenido". (Peabody Museum Collections Online). No obstante, el análisis de estos discursos supuestamente críticos del pasado requiere situarlos en los sucesos contemporáneos y en las prácticas reales de modificación de la relación de las instituciones con las personas y las culturas. 
los materiales del AEA a ello, pues en su interior se generaron disputas y cambios que no siempre tuvieron un desenlace homogéneo.

Finalmente, el AEA, como un área que desde su creación tuvo presentes las tensiones propias del espacio de poder que representa el archivo, es un ejemplo de cómo funciona la pulsión archivadora, de cómo se generan las historias archivísticas, de qué y cómo puede ser archivable y clasificable. Detenerse a describir estas prácticas y estos discursos nos permite comprender la experiencia de archivación del AEA como estrategia para situar el relato sobre la preservación de las culturas indígenas en diálogo con los discursos sobre el patrimonio nacional, la cual se desarrolla mediante una serie de maniobras de descubrimiento y ocultamiento de un conjunto de nociones sobre archivo, preservación y coleccionismo de la imagen producida mediante procedimientos fotográficos y audiovisuales.

\section{Referencias}

Ahued, Eduardo

1988 "El archivo Etnográfico Audiovisual", INI 40 años, México, Instituto Nacional Indigenista, pp. 540-549.

Baltazar Caballero, Ángel, Xilonen Luna Ruiz y Leticia Olvera

2010 El Cine Indigenista. Colección de Producciones Filmográficas Del Instituto Nacional Indigenista, México, Comisión Nacional para el Desarrollo de los Pueblos Indígenas.

Barrón Sanabria, Silvia Margarita

20II Catálogo fotográfico del archivo Alfonso Muñoz Jiménez, informe académico de actividad profesional para obtener el título de Licenciatura en Historia, México, Universidad Nacional Autónoma de México, recuperado de 132.248.9.195/ptd20I4/anteriores/filosofia/o721813/Index. html.

Becerril, Alberto

2015 "El cine de los pueblos indígenas en el México de los ochentas", Revista Chilena de Antropología Visual, 25, pp. 30-49, recuperado de http:// www.rchav.cl/2015_25_arto3_becerril.html.

Consejo Nacional de Evaluación de la Política de Desarrollo Social

$2018 \quad 40$ años de estrategias de coordinación interinstitucional para la política de desarrollo social en México, México, Consejo Nacional de Evaluación de la Política de Desarrollo Social, recuperado de https://www. 
coneval.org.mx/Evaluacion/IEPSM/Documents/Documento-completo-40-A-de-estrategias.pdf

Costa Cavalcanti, José

I972 Acta final, vir Congreso indigenista interamericano, Brasilia, Brasil, 7 a II de agosto de 1972, Anuario Indigenista, 32, recuperado de http:// www.nacionmulticultural.unam. $\mathrm{mx} / \mathrm{movimientosindigenas/docs/303.}$ pdf.

Diario Oficial de la Federación

I977 Acuerdo por el que se constituirá en Nacional Financiera, S.A., un fideicomiso, que se denominará Fondo Nacional para Actividades Sociales, 3I de enero, recuperado de https://www.dof.gob.mx/index_III.php?year $=1977 \&$ month $=$ or $\&$ day $=3 \mathrm{I}$.

Franco Rojas, María Elena

2020 "Imágenes en movimiento. La historia hecha cine. El Acervo de Cine y Video Alfonso Muñoz", en Mujer indígena, Videastas del presente, México, Instituto Nacional de los Pueblos Indígenas.

Gallois, Alice

2009 "Le cinéma ethnographique en France: le Comité du Film Ethnographique, instrument de son institutionnalisation? (1950-1970)", I895. Mille huit cent quatre-vingt-quinze, 58, doi: https://doi. org/10.4000/1895.3960

Garza Marcué, Rosa y José Luis Mariño

2017 “Ventana y Espejo Iv. Él es Dios”, En el volcán insurgente, 47, Pp. IO6-I27, recuperado de: $w w w$.enelvolcan.com/70-ediciones/047-enero-febrero2017/514-ventana-y-espejo-iv-el-es-dios.

Guía para la clasificación de los datos culturales

1989 México, Universidad Autónoma Metropolitana-Iztapalapa (colección de Antropología Social, Serie Manuales, I).

Instituto Nacional Indigenista, Comisión Nacional para el Desarrollo de los Pueblos Indígenas I948-20I2

2012 México, Comisión Nacional para el Desarrollo de los Pueblos Indígenas. Laferté, Gilles

2017 "Le film ethnographique comme archives", Études rurales, 199, doi: https://doi.org/I0.4000/etudesrurales.II474. 
Lewis, Stephen E.

2018 Rethinking Mexican Indigenismo: The INI's Coordinating Center in Highland Chiapas and the Fate of a Utopian Project, Albuquerque, University of New Mexico.

\section{Link, Adrianna Halina}

2016 Salvaging a record for humankind: urgent anthropology at the Smithsonian Institution, tesis de doctorado, Baltimore, Johns Hopkins University, recuperado de http://jhir.library.jhu.edu/handle/I774.2/40298.

Los materiales audiovisuales

1954 Acción indigenista, I3.

Massota, Carlos

2013 "QQuién necesita imágenes? Notas sobre la ansiedad etnográfica", Iluminuras, I4(32), pp. 30-42. doi: https://doi.org/IO.22456/1984-II9I.37734

Naranjo, Juan

2006 "Medir, observar, repensar. Fotografía, antropología y colonialismo", en Juan Naranjo (ed.), Fotografía, antropología y colonialismo (I8452006), Barcelona, Gustavo Gili.

Novelo, Victoria y Eduardo Maldonado

I997 "Laguna de dos tiempos, una experiencia de investigación filmada", en Ana María Salazar Peralta (coord.), Antropología visual, México, Universidad Nacional Autónoma de México-Instituto de Investigaciones Antropológicas.

Película del InI

1956 Acción indigenista, 34.

Piñó Sandoval, Ana

2013 El documental etnográfico mexicano, en María Guadalupe Ochoa (coord.), La construcción de la memoria. Historias del documental mexicano, México, Consejo Nacional para la Cultura y las Artes.

Romero Ugalde, Maricruz

199I La antropología en el cine etnográfico institucional. Análisis de la producción del Archivo Etnográfico Audiovisual del Instituto Nacional Indigenista 1978-1987, tesis para obtener el grado de Licenciatura en Etnología, México, Escuela Nacional de Antropología e Historia.

Rovirosa, José

I990 Miradas a la realidad, México, Universidad Nacional Autónoma de México-Centro Universitario de Estudios Cinematográficos. 
Ruiz Mondragón, Laura y Lorena Vargas Rojas

2003 Centro de Investigación, información y documentación de los Pueblos Indígenas de México. Guía General, México, Comisión Nacional para el Desarrollo de los Pueblos Indígenas.

Sierra Carrillo, Dora

I994 Cien años de etnografía en el museo, México, Instituto Nacional de Antropología e Historia.

Torres San Martín, Patricia

2018 Elena Sánchez Valenzuela, México, Universidad Nacional Autónoma de México-Centro Universitario de Estudios Cinematográficos.

Urrusti, Juan Francisco

2010 "Mara'Acame en mi memoria", en El indígena en el imaginario iconográfico, México, Comisión Nacional para el Desarrollo de los Pueblos Indígenas/Programa de las Naciones Unidas para el Desarrollo, pp. 24I-27I.

Vázquez Mantecón, Álvaro

2012 "Cine y propaganda durante el cardenismo", Historia y Grafía, 39, pp. 86-IoI, recuperado de https://www.revistahistoriaygrafia.com.mx/ index.php/HyG/article/view/36

\section{Documentos de archivo}

Convenio fonapas-Ini. Programa Ollin Yoliztli.198I. Instituto Nacional de los Pueblos Indígenas. Fondo Documental. FD 09/0230

Lineamientos Generales. Archivo Etnográfico Audiovisual del Instituto Nacional Indigenista. 1980. Instituto Nacional de los Pueblos Indígenas. Fondo Documental. FD 09/0728

\section{Páginas electrónicas}

Anthropology archives

https://naturalhistory.si.edu/research/anthropology/collections-overview/ anthropology-archives

Catálogo en línea de acervos del INPI http://acervos.inpi.gob.mx/cgi-bin/koha/opac-main.pl 
Historia de afiliación de la FIAF

https://www.fiafnet.org/pages/History/Map-FIAF-Institutions-History-Fu$11-$ Screen $\cdot$ html animauto $=$ yes $\&$ interval $=50 \&$ startdelay $=500$

History of the Human Studies Film Archives

https://web.archive.org/web/20130I27234352/http://www.nmnh.si.edu/naa/ guide/film_history.htm

Miradas al acervo. Cineteca Nacional

https://www.youtube.com/playlist?list=PLDl6JsaB KpPIT8FkuMoqKkknJ6VvHDpnH

Peabody Museum Collections Online https://pmem.unix.fas.harvard.edu:8443/peabody/

Rescate de la Colección Documental Etnográfica, Cineteca Nacional. (2013). https://www.adabi.org.mx/vufind/Record/expedienteIr97

The Film Study Center

https://filmstudycenter.org/about/

\section{Filmografía}

Arenas, José (director) (1956). Nuevos Horizontes. [Película]. México. INI.

Arenas, José (director) (1958). Peregrinación a Chalma. [Película]. México. SEP. Arenas, José (director) (1958). Todos somos mexicanos. [Película]. México. INI.

Castillo, Felipe Gregorio (director) (1937). Centro de Educación Indígena Kherendi Tzitzica. Flor de las peñas. [Película]. México. DAAP.

Castillo, Felipe Gregorio (director) (1937). Información Gráfica No. 1. [Película]. México. DAAP.

Cine documentos I.I.I.S.E.o (2). (1973) [Película]. México. Cine Difusión SEP. Furst, Peter T. (director) To find our life. (1969). [Película]. México.

Iñosavi. Tlaxiaco, tierra de nubes (1972). [Película]. México. Grupo Cine Labor López. Nacho (director). Misión de chichimecas (1970). [Película]. México.

Primeras acciones del INI (2009). [Video]. México. INI

Ramírez, Héctor (director) (1975). Los Triques de San Juan Copala. [Película]. México. Cine Difusión SEP.

Testimonio de un grupo (197I). [Película]. México. Grupo Testimonio.

Xantolo. Celebración del día de muertos (1973). [Película]. México. Grupo Cine Labor.

Julieta I. Martínez 
Investigadora independiente. Maestra y Licenciada en Historia por la Universidad Nacional Autónoma de México. Sus líneas de interés se centran en la historia social de y con imágenes en el siglo XIX, así como la catalogación de archivos fotográficos. Ha impartido charlas sobre fotografía en el siglo xix en el Museo Nacional de Arte, en la Escuela Nacional de Estudios Superiores campus Morelia y en el Museo de la Mujer de la Ciudad de México. Entre sus publicaciones se encuentran "Lineamientos para la descripción de fotografías" (2008) y "Las mestizas yucatecas en la obra de Désiré Charnay I860-I882" (2019).

Tzutzumatzin Soto Cortés

Investigadora Independiente. Maestra en Comunicación y Política por la Universidad Autónoma Metropolitana, Licenciada en Estudios Latinoamericanos por la Universidad Nacional Autónoma de México, cuenta además con un posgrado en Gestión, Preservación y Difusión de Colecciones fotográficas por la Universidad Autónoma de Barcelona. Sus líneas de estudio son: historia cultural de la formación de colecciones audiovisuales, preservación digital audiovisual y procesos de memoria comunitaria en archivos fotográficos. Entre sus publicaciones se encuentra "Humor: requisito de ingreso al archivo cinematográfico" (2015) y "El archivo y la promesa de memoria" (2017). Coordina el proyecto Experiencias de Archivo desde 2015. Actualmente se encarga de los Acervos Videográfico, Iconográfico y Digital de la Cineteca Nacional de México.

Citar como: Julieta I. Martínez López y Tzutzumatzin Soto Cortés (202I), "La imagen etnográfica en el Archivo Etnográfico Audiovisual del Instituto Nacional Indigenista", Iztapalapa. Revista de Ciencias Sociales y Humanidades, núm. 9I, año 42, julio-diciembre de 202I, ISSN: 2007-9176; pp. 15-38. Disponible en $<$ http://revistaiztapalapa.izt.uam.mx/index.php/izt/issue/ archive >. 